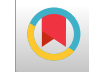

\title{
Psychometric Evaluation of the Persian Version of Body Image Coping Strategies Inventory
}

\author{
Malihe Farid ${ }^{1,2}$, Mahnaz Akbari Kamrani (iD ${ }^{1,3,{ }^{*}}$ and Sedigheh Jafarian ${ }^{4}$ \\ ${ }^{1}$ Social Determinants of Health Research Center, Alborz University of Medical Sciences, Karaj, Iran \\ ${ }^{2}$ Faculty of Medicine, Alborz University of Medical Sciences, Karaj, Iran \\ ${ }^{3}$ Department of Midwifery, Faculty of Nursing and Midwifery, Alborz University of Medical Sciences, Karaj, Iran \\ ${ }^{4}$ Farhangian University, Tehran, Iran \\ "Corresponding author: Social Determinants of Health Research Center, Alborz University of Medical Sciences, Eshteraki St., Baghestan Blvd., Karaj, Alborz, Iran. Tel/Fax: \\ +98-2634336007-9, Email: akbarikamrani21@gmail.com
}

Received 2017 June 12; Revised 2018 January 13; Accepted 2018 April 15.

\begin{abstract}
Background: Coping strategies are one of the key elements of mental health and have a significant relationship with mental health. Cash developed the body image coping strategies inventory (BICSI) to evaluate how individuals cope with threats or challenges about their body image.

Objectives: The purpose of this study was to examine the factor structure of the BICSI among Iranian female adolescents.

Methods: Participants were 537 high school students from Karaj, Iran, who volunteered for participating in this study. In order to achieve the aim of the study (factorial validity), the study population ( $\mathrm{n}=537$ participants) was split into two subsamples randomly. The subsamples were processed by the randomization function on SPSS (V. 22). AMOS Graphic (V. 20) software was used in order to examine the factorial validity of three BICSI factors.

Results: The Persian version of BICSI met all the requirements for confirming the quality of measurement. In addition, the factorability of constructs in the scale was confirmed as the results of confirmatory factor analysis showed good model fit indices (P $\leq$ 0.05). Cronbach's alpha as an internal consistency indicator was above 0.8 for all three subscales.

Conclusions: Based on the results of this study, the Persian version of BICSI was validated among Iranian adolescents.
\end{abstract}

Keywords: Body Image, Psychometrics, Translation, Iran

\section{Background}

Adolescence is the most significant and challenging stage of life $(1,2)$. It consists of a critical period of rapid physical, cognitive, social, and emotional maturation as the boy or girl prepares for adulthood $(3,4)$. Weight and body shape of adolescents, mainly in females, draw special attention due to various reasons like cultural, social, and racial factors (5). People in this period experience physical and psychological changes (6). The rapidity and the degree of these changes due to sexual and physical maturation may cause stress $(7,8)$, and growing height and weight and emergence of secondary characters in a short time can alter the individual's self-image (6). Body image is a subjective picture of one's own physical appearance established by both self-observation and noticing the reactions of others and is often characterized by physical appearance, size, shape, and general appearance $(9,10)$. Body image is culturally determined, and socio-cultural factors play an important role in the development and prevalence of body image dissatisfaction.

Perception of body image can influence the body image and can be a potential threat or challenge to body image. Individuals often develop and employ positive or negative cognitive and behavioral strategies to adjust or cope with this distressing issue $(11,12)$. Poor body image can raise the likelihood of health-risk behaviors such as poor diet and inadequate food intake (13). Females are more worried about their body image and have higher levels of stress in this regard as compared to males $(14,15)$.

Adolescents use coping strategies to realize and cope with many changes and to manage conditions in which there is a perceived difference between stressful problems and the available resources to deal with them $(3,16)$. Sufficient coping is dynamic for effective transition and conformation with adulthood (17). Coping strategies are key to mental health and have a significant relationship with it, and educational failure, assertiveness, forceful behaviors, emotional imbalances, and social loneliness of ado- 
lescents are due to ineffective coping with daily problems and interaction failures (3). Coping strategies are broadly categorized into emotion-focused, problem-focused, and avoidance coping strategies $(16,18)$. There are three coping strategies to adapt with body image and control image dissatisfaction and challenges, namely avoidance coping strategy, appearance fixing coping that includes efforts to hide or modify body composition to repair the defects or threats, and positive rational acceptance coping.

Cash et al. developed the body image coping strategies inventory (BICSI) to evaluate how individuals cope with threats or challenges about their body image. Results of a factor analysis on the BICSI revealed three body image coping strategies. First, an avoidance coping strategy that is characterized by an attempt to evade threats to one's body image thoughts and feelings. Second, an appearance fixing strategy such as efforts made to change one's appearance by concealing or correcting a flawed physical feature. Individuals using this strategy might allocate a great deal of time to change how they look. Third, a positive rational acceptance coping strategy that is defined as "mental and behavioral activities that emphasize the use of positive selfcare or rational self-talk and the acceptance of one's experiences" (19).

The BICSI includes 29 items, and avoidance strategy score is obtained based on eight items, appearance fixing strategy is evaluated using 10 items, and positive rational acceptance is rated using 11 items. All the items were rated using a 5-point Likert scale, including disagree, strongly disagree, no comment, agree, and strongly agree. Then, the total scores of each strategy are calculated and compared with one another. Any strategy that scores the highest, will be considered as the dominant one. The two strategies of fixing and avoidance are employed frequently by individuals to handle body image $(19,20)$. Probably, these strategies allow for temporary relief from body image-related stress. However, dependence on the avoidance and appearance fixing coping strategies tends to be related to risky outcomes, as well as lower self-esteem and disordered eating attitudes (19). Behavioral and skill training at an early age is likely to facilitate adjustment in life (21). Younger adolescents may be particularly vulnerable to stress because of being less skilled in evaluating situations and making decisions about coping strategies (22).

Greater use of maladaptive coping strategies than adaptive ones can result in negative consequences, like eating disorders and depression. As stressful thoughts and feelings that cause body image-related stress may be controlled by the use of correct coping strategies, it is recommended that adolescents be trained to adopt proper coping strategies to prevent ensuing psychological disorders. The current study was designed to assess the reliability and validity of the Persian version of the BICSI in adolescents. It is hoped that this Persian form help health authorities and educators have a better understanding of body image coping strategies based on the views of Iranian adolescents, which may assist in designing a framework for the development and implementation of programs to deal with body image challenges properly and in accordance with correct coping strategies.

\section{Objectives}

The purpose of this study was to examine the factor structure of the BICSI among Iranian female adolescents.

\section{Methods}

\subsection{Purpose of the Study}

The purpose of this study was to examine the factor structure of the BICSI among Iranian female adolescents. We hypothesized that the BICSI in the context of Iran would have an interpretable factor structure as other similar societies (western and non-western), where the reliability and validity of this survey instrument were reported.

\subsection{Sampling and Study Group}

The target population in this cross-sectional study was high school female students in Karaj, Iran. The participants were chosen using the two-stage random sampling method, where the first stage involved the selection of high school from four educational districts of Karaj based on the sample and population size. At each school, the samples were selected from the tenth, eleventh and twelfth grades. Based on the suggestion of some scholars $(23,24)$, the minimum sample size for models with large number of items (constructs) should be more than 500 cases. In addition, in order to avoid multivariate non-normality, the proportion of 15 participants for estimating parameter in the model is recommended. According to these two criteria, assuming a response rate of $25 \%$, and using the Cochran formula, the standard sample size was calculated to be 537 cases. The inclusion criteria comprised (1) female gender and (2) willingness to participate in the study. The exclusion criterion was not being in the age range of $14-18$ years old.

\subsection{Measure (Instrument)}

The respondents completed the BICSI. As described before, the 29-item BICSI measures three coping strategies using a 5-point Likert scale ranging from $1=$ disagree to 5 = strongly agree. Based on the aim of this study, at first the BICSI was translated into Persian, the official language 
of Iran. Then, it was back-translated by two independent translators. There were no differences between the primary translation and the back-translation. In order to verify face (content) validity, the original English and the Persian version of the scale were sent to 10 academic members in the area of health and psychology. They evaluated clarity, relevance, and simplicity of the individual items using the content validity index (CVI) assessment form on a 4point scale (25). All the experts confirmed the items, and there were a few recommendations that were applied, and consequently, all the items remained in the questionnaire.

In addition, content validity ratio (CVR) for measuring item-level validity was assessed. The experts rated each item using a 3-point rating system (1- The item is irrelevant, 2- The item is important but not essential, and 3- The item is essential). CVR was computed for each item. All the items were rated to be essential and remained in the questionnaire. Thus, the authors, independent translators, and three experts in the area of psychology health confirmed the face validity of the Persian form of the BICSI. In addition, the participants filled out a socio-demographic form, which contained items on age, maternal education, father's education, maternal occupation, and father's occupation.

\subsection{Statistical Analysis}

In order to achieve the aim of the study (factorial validity), the study population ( $\mathrm{n}=537$ participants) was randomly split into two subsamples. The subsamples were processed by the randomization function in SPSS 22. The demographic profiles of the initial samples are summarized in Table 1.

The first random subsample $(n=269)$ was applied to facilitate exploratory factor analysis (EFA). EFA was carried out in order to address the factor structure of 29 items of the Persian BICSI. Confirmatory factor analysis (CFA) was conducted on the second random subsample $(n=268)$. CFA was applied to test and confirm goodness-of-fit of the firstorder factor structure.

\subsection{Ethical Views}

Ethical approval was obtained from the Research Ethics Committee of Alborz University of Medical Sciences (ABZUMS.REC.1393.10). Ethical considerations have been taken into account, which included explaining the research objectives to the participants, obtaining informed consent form, and ensuring the participants of the voluntary nature of the study and confidentiality of their information. Permission for translation or modification of the BICSI was gained from Dr. Thomas F. Cash through Email (06/28/2016).

\begin{tabular}{|c|c|}
\hline Socio-Demographic Characteristics & No. (\%) \\
\hline \multicolumn{2}{|l|}{ Age, $y$} \\
\hline 14 & $59(11)$ \\
\hline 15 & $110(20.5)$ \\
\hline 16 & $147(27.4)$ \\
\hline 17 & $148(27.6)$ \\
\hline 18 & $73(13.6)$ \\
\hline \multicolumn{2}{|l|}{ Maternal education } \\
\hline Illiterate & $31(5.8)$ \\
\hline Primary and secondary & $234(43.6)$ \\
\hline High-school & $131(24.4)$ \\
\hline Associate degree and above & $141(26.3)$ \\
\hline \multicolumn{2}{|l|}{ Maternal occupation } \\
\hline Housewife & $443(83)$ \\
\hline Employed & $83(15.5)$ \\
\hline Retired & $8(1.5)$ \\
\hline \multicolumn{2}{|l|}{ Father's education } \\
\hline Illiterate & $12(2.3)$ \\
\hline Primary and secondary & $201(38)$ \\
\hline High-school & $153(28.9)$ \\
\hline Associate degree and above & $163(30.8)$ \\
\hline \multicolumn{2}{|l|}{ Father's occupation } \\
\hline Unemployed & $10(1.9)$ \\
\hline Worker & $69(13.2)$ \\
\hline Employee & $146(28)$ \\
\hline Retired & $59(11.3)$ \\
\hline
\end{tabular}

\section{Results}

\subsection{Primary Analyses}

Data for subsample 1 and subsample 2 were screened for missing values, multivariate outliers, and multivariate normality. Missing value tests showed that there were no missing values in the two datasets. Multivariate outliers were evaluated by calculating the Mahalanobis distance square (d-square $>2.5$ ). A review of the results showed that there were not any outliers in the sets of data. In addition, multivariate normality was checked using skewness and kurtosis criteria (skewness between \pm 2 and kurtosis $\leq$ as cited in Byrne's study (23)). All the data fell within the acceptable range, which reveals that no items were nonnormal. It can be concluded that all the data possessed the initial quality for conducting the inferential analysis. 


\subsection{Exploratory Factor Analysis}

Prior to conducting EFA, the suitability of the data was assessed by examining corrected item-total correlation coefficient test. Results of the correlation coefficient test showed that the data were more than 0.30 correlated. These results met the Tabachnik and Fidell's criterion ( $\mathrm{r} \geq$ 0.30) (26). In addition, Kaiser-Meyer-Olkin (KMO) measure of sampling adequacy and Bartlett's test of Sphericity were performed to confirm adequacy of sampling and factorability of the data, respectively (27). The results of Bartlett's test of Sphericity should be significant at $\mathrm{P} \leq 0$. 05. In this study, the results of Bartlett's test were significant at $\mathrm{P}<$ $0.001\left(\chi^{2}(406)=2133.950, \mathrm{P}<0.001\right)$. Thus, the dataset can be considered adequate for factor analysis (28). Furthermore, KMO was 0.811 at $\mathrm{P}<0.001$ level, which exceeds the recommended value of 0.60 (28). Generally, the results of Bartlett's test and KMO indicated that the data and sample size are highly proper for performing EFA. Results of EFA were as follows:

Principal component analysis (PCA) with varimax rotation on subsample 1 was administered to examine factor structure of the Persian version of the BICSI. In the first run of PCA, seven factor solutions with Kaiser's eigenvalue greater than 1.0 emerged. The seven factors explained $19.560 \%, 10.042 \%, 8.258 \%, 5.210 \%, 4.110 \%$, 3.746\%, and 3.593\% of the total variance, respectively, which accounted for $59.42 \%$ of the total variance. Results of Cattell's scree test of observed eigenvalues illustrated that the magnitudes of eigenvalues from fourth to seventh factors were slightly greater than 1.0. In fact, the scree plot identified four factors to be retained. Therefore, in order to make decisions about reducing the number of factors, parallel analysis (PA), retention method using 1000 random datasets, and confidence interval (CI) of $95 \%$ were applied. This statistical method was chosen in order to overcome the primary limitation of the Kaiser's eigenvalue criterion (29). As Table 2 shows, results of PA indicated that only 3 of 29 originally generated factors were greater than average eigenvalues generated from the random correlation matrix (30) and were retained for more investigations. Then, the second run of the EFA was conducted to produce three factor solutions and know about their order in the instrument. The second run of PCA for the BICSI revealed the presence of three components with eigenvalues exceeding 1.0, which totally explained $54.05 \%$ of the total variance. The three factors explained $31.03 \%, 17.02 \%$, and $6.01 \%$ of the variance, respectively. Using Cattell's scree test, it was also decided to retain the three components for further investigations. Note that this was previously supported by the results of PA in the first run of PCA in the present study (Table 2).

The three retained factors were rotated using the OR method in order to interpret the factor structure. Factor
Table 2. Comparing Extracted Eigenvalues from Principal Component Analysis Out put and Monte Carol Parallel Analysis Output

\begin{tabular}{lccc}
$\begin{array}{l}\text { Component } \\
\text { Number }\end{array}$ & $\begin{array}{c}\text { Actual } \\
\text { Eigenvalue from } \\
\text { PCA }\end{array}$ & $\begin{array}{c}\text { Random } \\
\text { Eigenvalue from } \\
\text { PA }\end{array}$ & Decision \\
\hline $\mathbf{1}$ & 11.012 & 1.738 & Accept \\
$\mathbf{2}$ & 2.698 & 1.643 & Accept \\
$\mathbf{3}$ & 1.782 & 1.570 & Accept \\
\hline
\end{tabular}

Abbreviations: PA, parallel analysis; PCA, principal component analysis.

loading of 0.50 and higher was considered significant for interpretation in this study (24). Inspecting both rotated component matrixes (i.e., structure and pattern matrixes) for the BICSI instrument revealed the following factors: (1) the first factor labeled "Appearance Fixing", a total of 10 items were loaded on this factor; (2) the second factor was labeled "Positive Rational Acceptance", a total of 11 items were loaded on this factor; and (3) the final factor was labeled "Avoidance", a total of eight items were loaded on this factor.

The BICSI items' factor loadings on the three factors are listed in Table 3. It is based on the pattern matrix generated by SPSS, version 22. As tabulated in Table 3, factor loading magnitudes of all the items of the three factors were more than 0.50, while there were cross-loadings on items $7 \mathrm{AF}, 11$ PRA, 15 PRA, 21 PRA, and 28 AV. These items were removed from the factor structure because they were loading differently from the considered constructs. For example, item 7 AF loaded on the factors appearance fixing and avoidance, respectively. Thus, after deleting items with cross loading on multiple factors, the final three-factor structure was created using 24 items.

The internal consistencies of the subscales were evaluated using the Cronbach's alpha. The values of Cronbach's alpha were $0.81,0.86$, and 0.92 for appearance fixing, positive rational acceptance, and avoidance, respectively. All the values were above 0.70 and in the acceptable range for reliability in social sciences (24).

In addition, the results obtained from component correlation matrix (SPSS, V. 22), which are presented in Table 4, showed that the factor PRA had a medium and positive correlation with $\mathrm{AF}(\mathrm{r}=0.477)$. The $\mathrm{AV}$ factor had a small and positive correlation with PRA factor $(\mathrm{r}=0.304)$. The AV and AF factors had a slight and positive correlation $(r=0.379)$. These findings indicated that the three factors of the BICSI are conceptually distinct enough from each other.

Overall, the aim of this study was to examine the reliability and validity of the Persian form of the BISCI among adolescents in Iran. The internal consistency reliability of the BISCI was excellent. Therefore, it was verified that each item belonged to their corresponding factor separately. As 


\begin{tabular}{|c|c|c|c|}
\hline Item No. & Factor 1 & Factor 2 & Factor 3 \\
\hline $1 \mathrm{AF}$ & 0.941 & & \\
\hline $2 \mathrm{AF}$ & 0.923 & & \\
\hline $3 \mathrm{AF}$ & 0.891 & & \\
\hline $4 \mathrm{AF}$ & 0.873 & & \\
\hline $5 \mathrm{AF}$ & 0.847 & & \\
\hline $6 \mathrm{AF}$ & 0.827 & & \\
\hline $7 \mathrm{AF}$ & 0.789 & & 0.316 \\
\hline $8 \mathrm{AF}$ & 0.756 & & \\
\hline $9 \mathrm{AF}$ & 0.732 & & \\
\hline $10 \mathrm{AF}$ & 0.694 & & \\
\hline 11 PRA & & 0.879 & 0.334 \\
\hline 12 PRA & & 0.847 & \\
\hline 13 PRA & & 0.793 & \\
\hline 14 PRA & & 0.767 & \\
\hline 15 PRA & & 0.736 & -0.327 \\
\hline 16 PRA & & 0.693 & \\
\hline 17 PRA & & 0.653 & \\
\hline 18 PRA & & 0.632 & \\
\hline 19 PRA & & 0.619 & \\
\hline 20 PRA & & 0.598 & \\
\hline 21 PRA & -0.323 & 0.573 & \\
\hline $22 \mathrm{AV}$ & & & 0.939 \\
\hline $23 \mathrm{AV}$ & & & 0.901 \\
\hline $24 \mathrm{AV}$ & & & 0.865 \\
\hline $25 \mathrm{AV}$ & & & 0.833 \\
\hline $26 \mathrm{AV}$ & & & 0.821 \\
\hline $27 \mathrm{AV}$ & & & 0.773 \\
\hline $28 \mathrm{AV}$ & 0.387 & & 0.742 \\
\hline $29 \mathrm{AV}$ & & & 0.658 \\
\hline
\end{tabular}

Abbreviations: AF, appearance fixing; AV, avoidance; PRA, positive rational acceptance.

\begin{tabular}{|c|c|c|c|}
\hline \multirow[t]{2}{*}{ Variables } & \multicolumn{3}{|c|}{ CE } \\
\hline & $\mathbf{A F}$ & PRA & AV \\
\hline 1. AF & 1 & & \\
\hline 2. PRA & $0.477^{\mathrm{a}}$ & 1 & \\
\hline 3. AV & $0.379^{\mathrm{a}}$ & $0.304^{\mathrm{a}}$ & 1 \\
\hline
\end{tabular}

a result, the BISCI is suitable for use in Iran. In addition, the results of EFA confirmed the extraction of three factors in the Persian form of BICSI with 24 items. This result is consistent with those of Cash et al. (19), which supported a three-factor solution. Therefore, the Persian version of BICSI can be considered as a scale with three factor solutions to be used in Iran.

\subsection{Confirmatory Factor Analysis}

In order to confirm the factorial structure of the three BICSI latent factors and their observed variables (i.e., 24 items of the scale) produced by the EFA, CFA using AMOS Graphic (V. 20) was performed on subsample 2.

The specified first-order CFA was depicted to assess each item's factor loadings. As a rule of thumb, items with a factor loading of less than 0.50 should be removed from the model in order to achieve the best model fit (24). The results of CFA for the 24 items of BICSI (Persian form) showed that all the factor loadings were more than 0.50 or very close to 0.50 (i.e., $r=0.53$; Figure 1 , Fit indices for model were $\frac{\chi^{2}}{d f}=2.767, \mathrm{P}=0.000, \mathrm{GFI}$ [goodness-of-fit in$\operatorname{dex}]=0.877$, CFI $[$ comparative fit index $]=0.831$, RMSEA $[$ root means square error of approximation $]=0.083$, IFI $=0.833$ ).

Thus, all the items remained in the model. Also, fit indices were $\left(\frac{\chi^{2}}{d f}=2.767, \mathrm{P}<0.001, \mathrm{GFI}=0.877, \mathrm{CFI}=0.831\right.$, RMSEA $=0.083$, IFI [incremental fit index] $=0.833$ ). RMSEA should be less than 0.08 (23), and the GFI, CFI, and IFI indices should be equal or more than 0.90 , indicating acceptable fit values (24). Therefore, the assessment of fit indices recommended model fit is not adequate. In order to increase model goodness-of-fit, item parceling was conducted by performing a partial disaggregation method (i.e., homogeneous parcels). Nine items of appearance fixing, eight items of positive rational acceptance, and seven items of avoidance were average and parceled on their corresponding observed variable (i.e., $\mathrm{AF}, \mathrm{PRA}$, and $\mathrm{AV}$ ) in the first-order CFA. The results of first-factor CFA for items after parceling indicated better model fit indices $\left(\frac{\chi^{2}}{d f}=1830, \mathrm{P}<\right.$ $0.001, \mathrm{GFI}=0.932, \mathrm{CFI}=0.926, \mathrm{RMSEA}=0.0058, \mathrm{IFI}=0.927)$. Although the results of CFA confirmed the factorial structure of the Persian form of BICSI, following Chiu and Wang recommendation for more validation of the measurement model, the authors examined convergent and divergent validity, as well as construct reliability (31). Contract reliability was assessed by composite reliability (CR). As shown in Table 5, CR estimates whether all factors (contracts) met the cut-off value of between 0.6 and 0.7 , which is acceptable (24), and average variance extracted (AVE) exceeds the recommended level of 0.5 (32). Therefore, it can be concluded that each construct has adequate convergence.

Finally, divergent validity was examined by addressing 


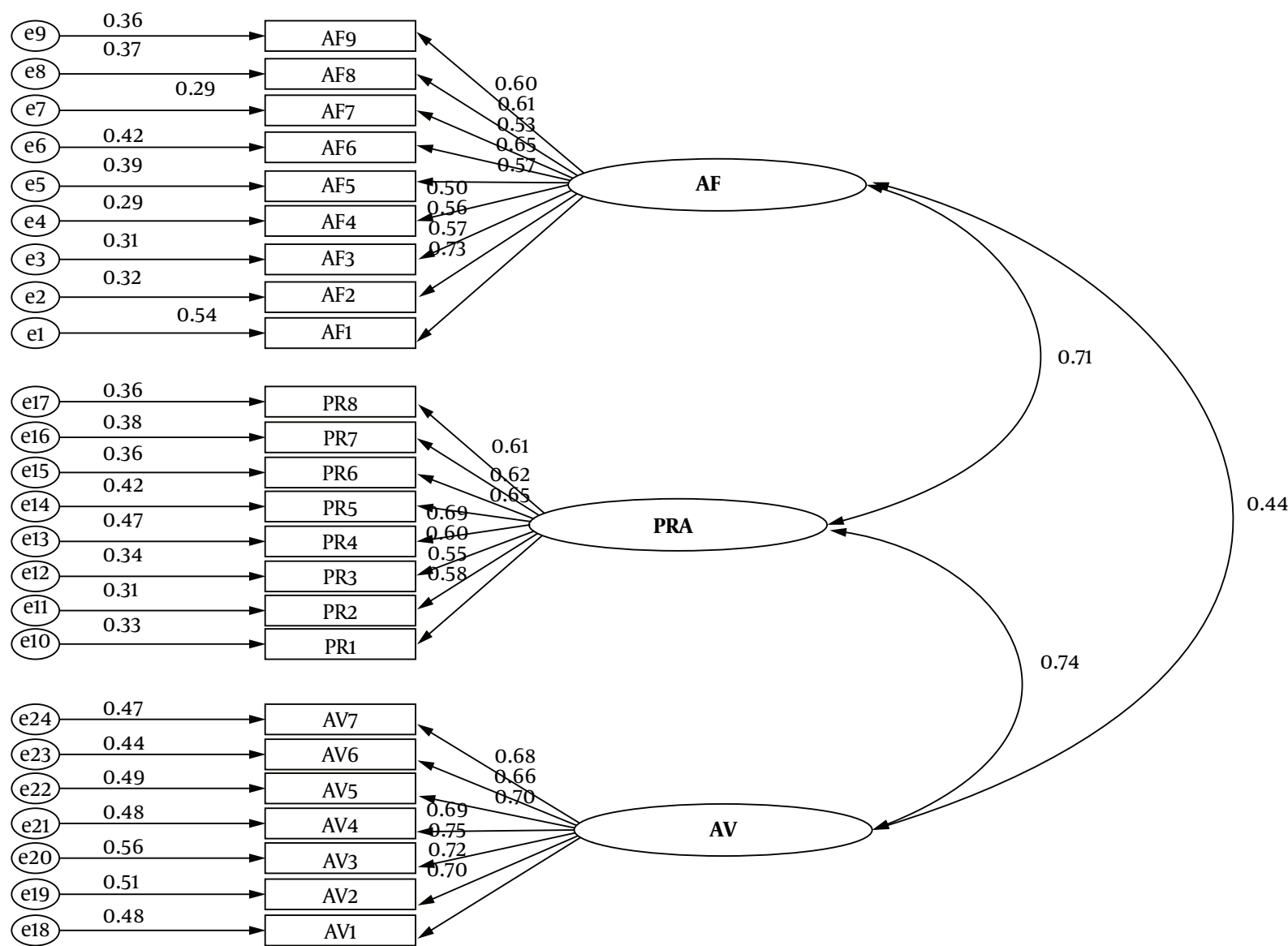

Figure 1. Specified first order CFA.

\begin{tabular}{|c|c|c|}
\hline \multirow[t]{2}{*}{ Constructs } & \multicolumn{2}{|c|}{ Convergent Validity } \\
\hline & Composite Reliability & AVE \\
\hline $\mathbf{A F}$ & 0.866 & 0.619 \\
\hline PRA & 0.788 & 0.559 \\
\hline AV & 0.728 & 0.573 \\
\hline
\end{tabular}

the criterion that explains "diagonal elements in the calculated table should be larger than off-diagonal elements". Table 6 summarized the squared correlation and AVE for each construct.

\section{Discussion}

The aim of this study was to examine the reliability and validity of the Persian form of the BISCI among adolescents

\begin{tabular}{lccc}
\hline \multicolumn{4}{l}{ Table 6. Discriminate Validity Coefficient } \\
\hline Latent Constructs & AF & PRA & AV \\
\hline AF & $(0.619)$ & 0.350 & 0.320 \\
PRA & 0.190 & $(0.599)$ & 0.291 \\
AV & 0.180 & 0.540 & $(0.677)$ \\
\hline
\end{tabular}

Abbreviations: AF, appearance fixing; AV, avoidance; PRA, positive rational acceptance.

${ }^{\text {a }}$ Diagonal elements are the square root of average variance extracted(AVE). Offdiagonal elements are the correlations among the constructs.

in Iran. The internal consistency of the BISCI was excellent. Therefore, it was verified that each item belonged to its corresponding factor separately. As a result, the BISCI is suitable for use in Iran. In addition, the results of EFA confirmed extraction of three factors in the Persian form of the BICSI instrument with 24 items. This result is consistent with those of Cash et al. (19), which supported threefactor solution. Therefore, the Persian version of the BICSI 
can be considered as a scale with a three-factor solution to be used in Iran.

Generally, the Persian form of the BICSI meets all the requirements for confirming the quality of measurement (i.e., reliability, as well as convergent and discriminant validity) as recommended by Chiu and Wang (31). In addition, the factorability of the constructs in the scale is confirmed as results of CFA showed good model fit indices. Therefore, based on the results of this study, the Persian form of the BICSI was validated among Iranian adolescents.

\subsection{Limitations}

Because of some restrictions, this questionnaire was not applied to rural settings and in mixed-gender groups, thus, future studies are recommended to evaluate this questionnaire in rural areas of Iran and in Iranian adolescent boys.

\subsection{Conclusion}

Despite the growing concern of researchers and scholars to examine the validity and reliability of the BICSI in western and nonwestern societies, much is yet to be done to ensure structure factor of this instrument. We attempted to narrow this gap in a non-western society such as Iran. In sum, this study indicated that the factor structure of the BICSI with 24 items on three factors is valid in the Iranian context. The findings of EFA and CFA were consistent with a large body of literature in western studies. Simultaneously, the Persian form of the BICSI showed high levels of validity and reliability. Therefore, the 24-item form can be used as a reliable and valid instrument for measuring body image coping strategies in clinical studies in Iran, although the items 7 AF, 11 PRA, 15 PRA, 21 PRA, and $28 \mathrm{AV}$ were discarded. Thus, future studies are required (as mentioned in reference 19) to indicate the main cause of cross loading problems of the BICSI instrument in Iran.

\section{Acknowledgments}

This paper was part of a research project conducted with the support of Alborz University of Medical Sciences (ID number: 2427645). We wish to thank the participants for their cooperation in this research.

\section{Footnotes}

Authors' Contribution: All the authors have made a significant contribution to the article. Malihe Farid and Mahnaz Akbari Kamrani contributed to the study conception, design, data acquisition, and drafting of the manuscript.
Sedigheh Jafarian conducted the statistical analyses. Malihe Farid and Mahnaz Akbari Kamrani supervised the study. The final version of the manuscript has been approved by all authors.

Declaration of Interest: None declared.

Clinical Trial Registration Code: None declared.

\section{References}

1. Cappa C, Wardlaw T, Langevin-Falcon C, Diers J. Progress for children: a report card on adolescents. Lancet. 2012;379(9834):2323-5. doi: 10.1016/S0140-6736(12)60531-5. [PubMed: 22538182].

2. Soponaru C, Bojian A, Iorga M. Gender differences regarding body image, stress and coping strategies in adolescence. Arch Medl Sci Civil Dis. 2016;1(1):36-42. doi: 10.5114/amscd.2016.59897.

3. Sharifi M, Kaveh M. The effect of teaching coping strategies on the mental health of 13-17 male adolescents living in boarding houses of Tehran. Procedia Social and Behav Sci. 2013;84:514-9. doi: 10.1016/j.sbspro.2013.06.595.

4. Hockenberry MJ, Wilson D. Wong's essentials of pediatric nursing. 9th ed. Elsevier - Health Sciences Division; 2014.

5. Streigel-Moore RH, Smolak L. Gender, ethnicity, and eating disorders. In: Fairburn CG, Brownell KD, editors. Eating disorders and obesity: A comprehensive handbook. New York City, New York, United States: The Guilford Press; 2002.

6. Carson VB. Mental health nursing: The nurse-patient journey. 2nd ed. Philadelphia, Pennsylvania, United States: W.B. Saunders; 2000.

7. Huli PR. Stress management in adolescence. J Res Human Social Sci. 2014;2(7):50-7.

8. Abbott BD, Barber BL. Differences in functional and aesthetic body image between sedentary girls and girls involved in sports and physical activity: Does sport type make a difference? Psychol Sport Exerc. 2011;12(3):333-42. doi: 10.1016/j.psychsport.2010.10.005.

9. Merriam-Webster dictionary. [cited 2009 July 6]. Available from: https: //www.merriam-webster.com/.

10. Boyd MA. Psychiatric nursing: Contemporary practice. Philadelphia, Pennsylvania, United States: Lippincott Williams \& Wilkins; 2002.

11. Chen LJ, Fox KR, Haase AM. Body image and physical activity among overweight and obese girls in Taiwan. Women's Stud Int Forum. 2010;33(3):234-43. doi:10.1016/j.wsif.2010.01.003.

12. Hampel P, Petermann F. Perceived stress, coping, and adjustment in adolescents. $J$ Adolesc Health. 2006;38(4):409-15. doi: 10.1016/j.jadohealth.2005.02.014. [PubMed: 16549302].

13. Megalakaki O, Mouveaux M, Hubin-Gayte M, Wypych L. Body image and cognitive restraint are risk factors for obesity in French adolescents. Eat Weight Disord. 2013;18(3):289-95. doi: 10.1007/s40519-0130027-x. [PubMed: 23807773].

14. Cash TF. Cognitive-behavioral perspectives on body image. In: Cash TF, Pruzinsky T, editors. Body image: A handbook of theory, research, and clinical practice. New York City, New York, United States: Guilford Publications; 2002.

15. Murray KM, Byrne DG, Rieger E. Investigating adolescent stress and body image. J Adolesc. 2011;34(2):269-78. doi: 10.1016/j.adolescence.2010.05.004. [PubMed: 20627369].

16. Fatima S, Tahir S. Comparison of coping strategies used by adolescents on state and trait anxiety. FWUJ Social Sci. 2013;7(2):165-74.

17. Ibrahim El Azzab SESH. A psychological counseling program to the impact of coping strategies on life satisfaction among adolescents. Egypt J Nurs. 2015;10(1). e6105.

18. Carver CS, Connor-Smith J. Personality and coping. Annu Rev Psychol. 2010;61:679-704. doi: 10.1146/annurev.psych.093008.100352. [PubMed: 19572784]. 
19. Cash TF, Santos MT, Williams EF. Coping with body-image threats and challenges: validation of the Body Image Coping Strategies Inventory. J Psychosom Res. 2005;58(2):190-9. doi: 10.1016/j.jpsychores.2004.07.008. [PubMed:15820848].

20. Melnyk SE, Cash TF, Janda LH. Body image ups and downs: prediction of intra-individual level and variability of women's daily body image experiences. Body Image. 2004;1(3):225-35. doi: 10.1016/j.bodyim.2004.03.003. [PubMed: 18089155].

21. Rawat R, Sagar R, Khakha DC. Puberty: A stressful phase of transition for girls. IOSR J Nurs Health Sci. 2015;4(5):7-12. doi: 10.9790/195904530712.

22. Williams K, McGillicuddy-De Lisi A. Coping strategies in adolescents. J Appl Dev Psychol.1999;20(4):537-49. doi:10.1016/s0193-3973(99)000258.

23. Byrne BM. Structural equation modeling with AMOS: Basic concepts, applications and programming. Multivariate applications book series. Mahwah, New Jersey, United States: Lawrence Erlbaum Associates Publishers; 2010.

24. Aishah Radin A Rahman RS, Lope Pihie ZA. Validation of a social entrepreneurial self-efficacy. IOSR J Bus Manage. 2014;16(11):133-41. doi: $10.9790 / 487 \mathrm{x}-16112133141$.

25. Sedaghati Kesbakhi M, Rohani C, Mohtashami J, Nasiri M. Validity and reliability of the Jefferson scale of empathy, nursing student version $\mathrm{R}$ in a sample of Iranian oncology nurses. Nurs Midwifery Stud. 2017;6(2) e39505.

26. Tabachnick BG, Fidell LS. Using multivariate statistics. 6th ed. Boston, Massachusetts, United States: Allyn \& Bacon/Pearson Education; 2013.

27. Nejati M, Nejati M. Assessment of sustainable university factors from the perspective of university students. JClean Prod. 2013;48:101-7. doi: 10.1016/j.jclepro.2012.09.006.

28. Pallant J. SPSS survival manual: A step by step guide to data analysis using SPSS for Windows version 15. 3rd ed. Crows Nest, Australia: Allen \& Unwin; 2007.

29. Ledesma RD, Valero-Mora P. Determining the number of factors to retain in EFA: An easy-to-use computer program for carrying out parallel analysis. Pract Assess Res Eval. 2007;12(2):1-11.

30. Williams B, Onsman A, Brown T. Exploratory factor analysis: A fivestep guide for novices. Australas J Paramedic. 2010;8(3).

31. Chiu CM, Wang ETG. Understanding Web-based learning continuance intention: The role of subjective task value. Inf Manage. 2008;45(3):194-201. doi:10.1016/j.im.2008.02.003.

32. Ho $\mathrm{CH}$, Swan K. Evaluating online conversation in an asynchronous learning environment: An application of Grice's cooperative principle. Internet High Educ. 2007;10(1):3-14. doi: 10.1016/j.iheduc.2006.11.002. 